Article

\title{
Radiation in the Optical and UHF Range Emitted by Partial Discharges
}

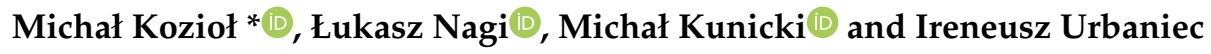 \\ Faculty of Electrical Engineering, Automatic Control and Informatics, Opole University of Technology, \\ Proszkowska 76, 45-758 Opole, Poland; l.nagi@po.edu.pl (Ł.N.); m.kunicki@po.edu.pl (M.K.); \\ i.urbaniec@po.edu.pl (I.U.) \\ * Correspondence: m.koziol@po.edu.pl
}

Received: 9 October 2019; Accepted: 10 November 2019; Published: 14 November 2019

\begin{abstract}
This paper presents the results of analysis of a solid dielectric's influence on the phenomena associated with the signals emitted by surface partial discharges. Three types of electrode systems were tested, in which solid dielectrics made of pressboard, Teflon, and glass were used. The emission of such signals as radio waves in the Ultra high frequency (UHF) range and optical radiation was analyzed. The measurements were carried out in the insulation systems most commonly used in electrical power equipment, i.e., mineral oil and air. UHF and optical spectrophotometry methods were used to register the emitted signals. The obtained results indicate that the type of material from which the dielectric solid is made may have a potential impact on some ranges of emitted electromagnetic waves during the surface electrical discharges. The research topic undertaken is important in issues associated with high-voltage insulation systems and in particular with surface discharges, which are often the cause of their damage.
\end{abstract}

Keywords: solid dielectrics; optical emission; UHF emission; surface partial discharges

\section{Introduction}

In the isolation medium, there are situations where two points of different potential are created. Most often, it is damage to the insulation system, which can be caused mechanically or through manufacturing defects. Between these two points, there can be a physical phenomenon called partial discharge (PD). The generation of PD leads to more and more damage to the insulator and, as a result, can lead to a complete discharge and total damage to both the insulator and electrical equipment. This happens, for example, in the case of insulation of power cables in networks or electrical equipment. Damage, as mentioned above, may result from poor quality of the materials used or may be generated independently by a number of different factors. Failures are troublesome for several reasons. The most important of these are grid shutdowns or energy cuts. It is a typical phenomenon in old or underdeveloped networks. More dangerous are the failures that lead to explosions. This causes even greater material and economic damage and, above all, is dangerous from the point of view of human health and life. PD diagnostics are based on early detection of these phenomena. Some detect the phenomenon at a very early stage, but do not provide the exact location. Other methods can be used to identify the location of a fault with great accuracy, but it is not possible to detect defects at an early stage. Important for economic factors are both the detection of PD in the initial phases of formation and its exact location. The faster it is detected, the faster it can be reacted to.

Today's diagnostics for detecting faults that generate partial discharge are based on detecting the phenomena associated with the generation of the discharge. The diagnostic methods presented in this article are optical, UHF, and electrical. The main emphasis is placed on UHF and optical measurements as the latest solutions [1]. Electrical measurements are used as a reference. PD detection by means of, 
e.g., apparent charge is a proven method and is described in the standard [2]. Therefore, it is good to apply the results of the new methods to the well-known ones. Measurements of optical signals in the range of visible light and UHF signals have an additional advantage in the form of electromagnetic (EM) signals in different frequency ranges. The same type of signal measured by two different methods based on different wave frequencies can give additional important information about the total energy of the phenomenon, such as PD. Both electric and UHF methods are already used on real objects, although the UHF method is still under development [3,4]. The optical method is still a laboratory method at the moment. Research on the detection of partial discharges outside the optical, UHF, and electrical methods is carried out in several directions. Acoustic [5,6] and Dissolved gas analysis (DGA) methods are also frequently used. Many of the gas dielectrics are decomposed. Methods such as DGA [7] and Density functional theory (DFT) [8] help to understand how they decompose under the influence of $\mathrm{PD}$ and what the environmental impact of byproducts is. The piezoelectric sensor-based acoustic method is used to detect the acoustic waves accompanying PD. An important element of such tests is vibration acoustics and measurement of the intensity and direction of the signal that is generated. However, the UHF and optical methods [9-12] used by the authors of this article focus on another phenomenon accompanying the generation of partial discharges. The registration of electromagnetic waves of various frequencies is a relatively new method. The optical method uses a spectrophotometer and fiber optics. The same fiber can be used to detect Acoustic emission (AE) signals [13]. The UHF method recording signals from this range of EM waves is one of the most recently described and, in particular, implemented methods of PD detection and location. It has been found to remain on real objects, although it has been developed in laboratories [14]. The optical method consists of setting the optical fiber in the direction of the electrical discharge source and recording the optical spectrum in the range depending on the capabilities of the spectrophotometer matrix, from visible light and near ultraviolet (UV) light to wider ranges. This method is new, but descriptors have already been developed on its basis and are an effective method for detecting and locating PDs. Another detector used to record electromagnetic radiation is the scintillation detector. When stimulating the spark gap system in the laboratory to produce partial discharges, radiation in the range above UV radiation is generated [15]. Radiation with ionizing energy occurs during the discharge and its propagation may cause the occurrence of subsequent events. High-energy radiation may cause greater degradation of insulation beyond the PD itself through its destructive effect on the material with which it interacts. The exact effect of this component of the EM wave from the discharges on PD behavior and damage to matter is yet to be investigated. However, $\mathrm{X}$-rays were used in laboratory tests as an impulse to accelerate the generation of PD in specially prepared materials with defects. The energy supplied by the radiation from this spectrum ionizes the particles in free spaces or air gaps in the insulation and causes more rapid discharges [16].

Solid dielectrics as insulation material have an important task in high-voltage insulation systems. The safety of both people and equipment depends on their durability. These materials are also exposed to various types of electrical discharges where, depending on the mechanisms of the formation of these discharges and the type of material of which the dielectric is made, they can have an impact on the phenomena associated with electrical discharges.

New methods, devices, and measuring systems for PD detection are developed and tested both in the laboratory and on commercial devices. Laboratories are modeling the most common types of spark discharge in different environments. Damage to solid and liquid insulators is simulated by physically damaged or degraded components from real-life systems. Gaseous, liquid, and solid insulations are used in research and testing. Liquids in the form of mineral oils or natural and synthetic esters are also used [17]. In real objects, except for insulation in the form of oils or esters, solid insulators in the form of Teflon or various types of paper are often used, e.g., pressboard [18-20].

The undertaken research topic is aimed at examining the impact of the type of material from which the solid dielectric is made on the signals emitted by surface partial discharges, such as radio waves in the UHF range and optical radiation. The obtained results will contribute to a better understanding of 
the mechanisms of surface partial discharges and to the improvement of currently used high-voltage diagnostic methods. They can also be useful for designing high-voltage insulation systems.

\section{Measuring system}

As part of the research, the influence of the type of solid dielectric material on the emitted signals during surface partial discharges was investigated. Three types of solid dielectrics materials (Table 1) were analyzed, which, together with the supply electrode and the ground electrode, formed a system for surface partial discharges. High voltage was applied to a cylindrical electrode with a diameter of $10 \mathrm{~mm}$. The second electrode (grounded) was a plate in the shape of a flat cylinder with a thickness of $9.0 \mathrm{~mm}$ and a base diameter of $70 \mathrm{~mm}$. Between the electrodes was a solid dielectric with a thickness of $8 \mathrm{~mm}$ and dimensions $90.0 \times 90.0 \mathrm{~cm}$. The electrode system was supplied by a regulated transformer with a rated voltage of $110 \mathrm{kV}$. The measurements were carried out in brand new mineral oil and in the air in laboratory conditions.

Table 1. Basic properties of the applied dielectrics.

\begin{tabular}{cccc}
\hline Material Properties & Pressboard & Teflon & Glass \\
\hline Density $\left(\mathrm{g} / \mathrm{cm}^{3}\right)$ & $1.0-1.3$ & 2.2 & 2.5 \\
Permittivity $(-)$ & 5.8 & 2.1 & $4-10$ \\
\hline
\end{tabular}

An optical spectrophotometer HR4000 was used to register optical radiation, which allowed registration in the wavelength range of $200 \mathrm{~nm}$ to $1100 \mathrm{~nm}$ Ultraviolet-Visible-Near Infrared (UV-VIS-NIR). A polymer optical fiber (POF) was used as the measurement probe for optical signals.

The MPD 600 system was used to register radio waves in the UHF range. The UVS610 probe was used to register radio waves in the UHF range in mineral oil. Measurements in the air were carried out using the Watson W-881 antenna. The UHF608 converter was used for acquisition of measurement data. Radio waves were analyzed in the range of $250 \mathrm{MHz}$ to $750 \mathrm{MHz}$ in both oil and air environments.

The diagram of the measurement system is presented in Figure 1.

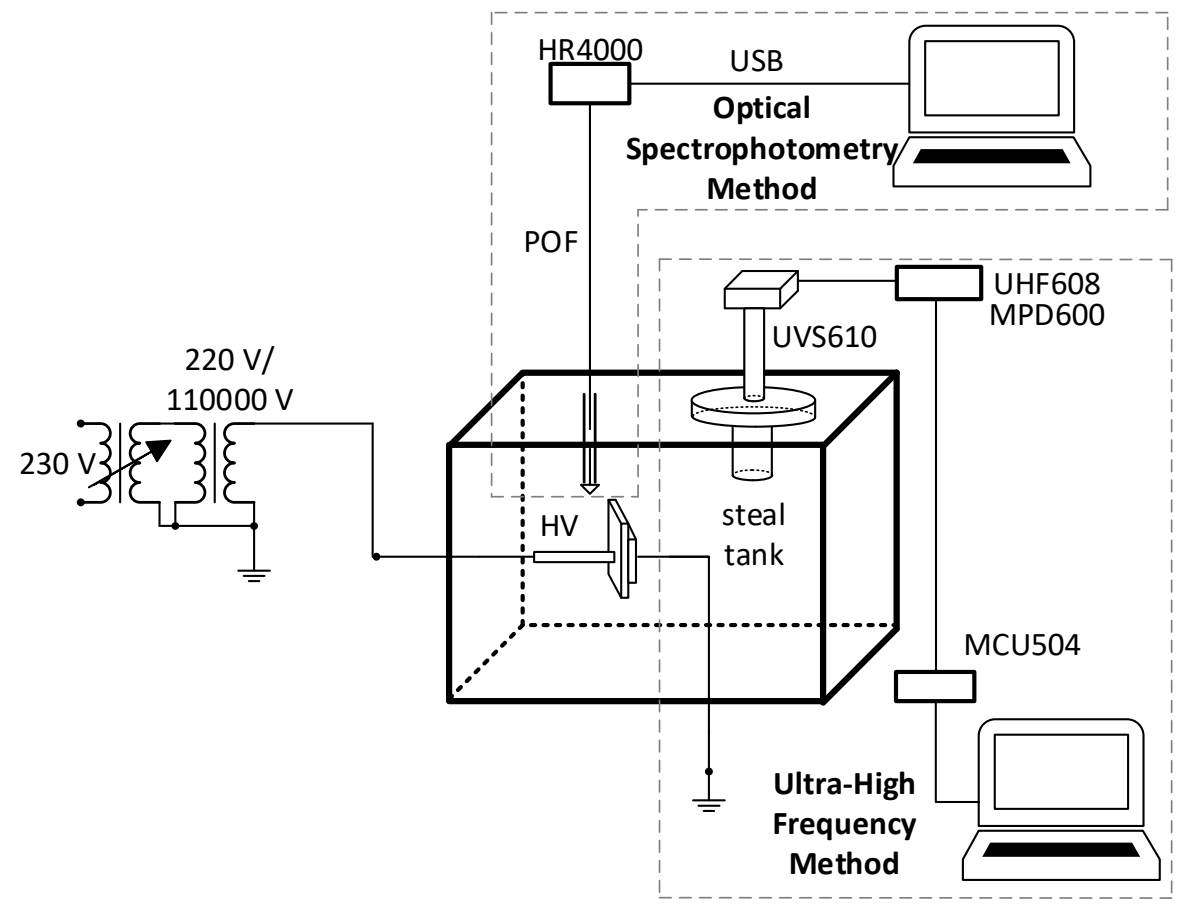

Figure 1. Diagram of the measuring system. 


\section{Measurements, Results, and Discussion}

\subsection{UHF Measurements}

\subsubsection{Measurements in the Insulating Oil}

The tests were carried out in a brand new mineral oil in which surface partial discharges were generated. Metrological conditions were identical for all tested systems, i.e., the ambient temperature and oil temperature were $20{ }^{\circ} \mathrm{C}$, and the humidity was 53\%. The first phase of UHF emission measurements included the analysis of individual frequency ranges of the measurement probe in order to determine the bands for which the intensity of emitted radio waves was the highest. On this basis, two central frequencies were selected: $450 \mathrm{MHz}$ and $570 \mathrm{MHz}$. These bands are a repeatable indicator in all studied systems and are characterized by the highest activity during the generation of surface partial discharges.

For each system, a series of measurements for three voltage values were made and background signals were registered. For measurements in oil where surface partial discharges were generated on solid dielectrics, the voltages were as follows: pressboard (PBP) $-23 \mathrm{kV}, 27 \mathrm{kV}$, and $31 \mathrm{kV}$, Teflon (PTFE) $-20 \mathrm{kV}, 26 \mathrm{kV}$, and $30 \mathrm{kV}$, and for glass (GLS), they were $22 \mathrm{kV}, 26 \mathrm{kV}$, and $30 \mathrm{kV}$. Each of the used dielectrics had a thickness of $6 \mathrm{~mm}$. Figure 2 shows the UHF level (lvl) for the measurements carried out where the dielectric was pressboard. The highest activity can be observed at $310 \mathrm{MHz}$, $360 \mathrm{MHz}, 380 \mathrm{MHz}, 480 \mathrm{MHz}, 530 \mathrm{MHz}$, and $570 \mathrm{MHz}$, regardless of the voltage applied. The voltage itself increased only UHF lvl by a few dB. Only for the highest of the presented voltages, there was still activity around the $670 \mathrm{MHz}$ band. Figure 3a,b shows UHF signals recorded in the oil system using Teflon and glass as a solid dielectric. For PTFE, it can be observed that apart from some central frequencies such as $310 \mathrm{MHz}, 355 \mathrm{MHz}$, around $400 \mathrm{MHz}, 480 \mathrm{MHz}$, and 560-570 MHz, there are also frequencies above $600 \mathrm{MHz}$. The recorded activity in the $610 \mathrm{MHz}$ and $670 \mathrm{MHz}$ bands, however, concerns voltages from $26 \mathrm{kV}$ upwards. It can also be noticed that for voltages from $26 \mathrm{kV}$, the UHF level is quite stable and independent of voltage. Perhaps if the PD activity were to change over a long period of time, it would depend on the voltage applied. The biggest divergences between the UHF levels depending on the voltage are found for glass. The differences are a few $\mathrm{dB}$, but at each voltage value and at each frequency where we can notice PD activity. As for PBP and PTFE, for GLS, it can also be observed that at the highest of the applied voltage values generating PD, UHF activity peaks appear in bands above $600 \mathrm{MHz}$. The highest stability of Teflon can be explained by the fact that it is the most resistant insulating material used in high-voltage tests during the generation of surface discharges. This is mainly due to its lowest permittivity in comparison with other tested solid dielectrics.

During the generation of partial discharges in oil, apart from recording UHF and optical signals, the number of counts of PD acts for each dielectric material used was also recorded (Figure 4a). In order to better illustrate the measurement results, the approximation model was used in the presented characteristics. The accuracy of the model indicates the coefficient of determination $\mathrm{R}^{2}$. Figures $4 \mathrm{~b}$ and 5 show the average and maximum amplitude of UHF signals. Both characteristic values are used as good descriptors to describe the PD phenomenon [21]. Both the mean and maximum UHF amplitude values for Teflon increased with the voltage generating partial discharges. These values are slightly different for pressboard and glass. While the average value increases as the voltage increases for both the glass and the pressboard, the maximum amplitude value first increases and then, for the pressboard, decreases, according to the model. For the glass, the growth rate decreases and it looks as if the graph strives for an asymptotic value (perhaps some saturation). 


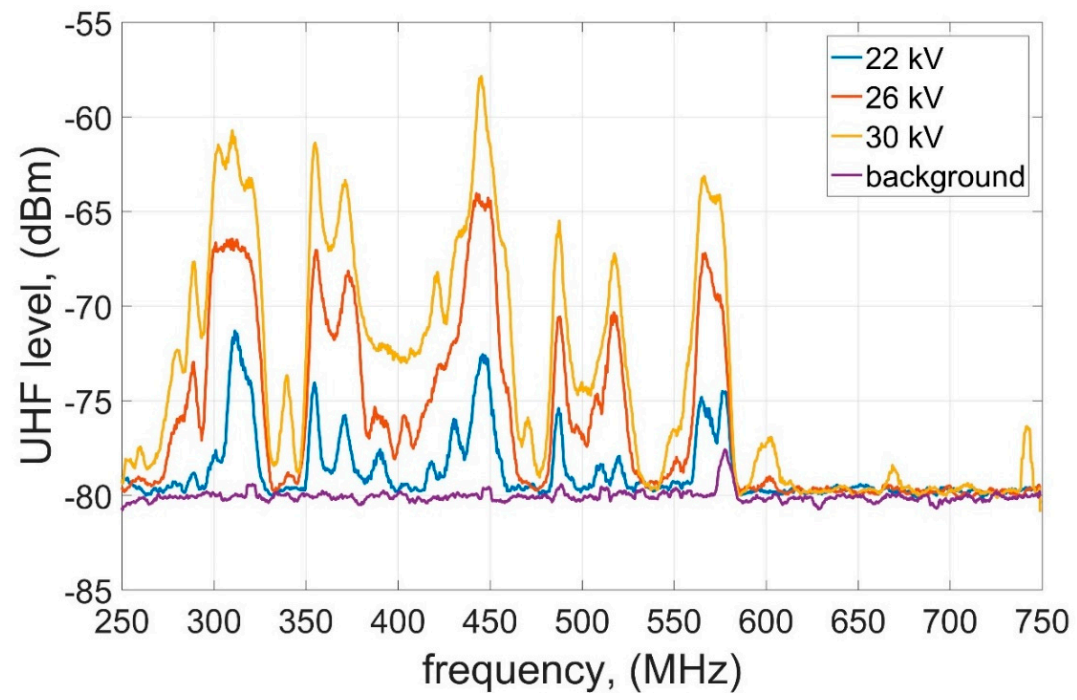

Figure 2. Levels of Ultra high frequency (UHF) signals emitted by surface partial discharges, generated in mineral oil on an electrode system with a solid dielectric made of pressboard.

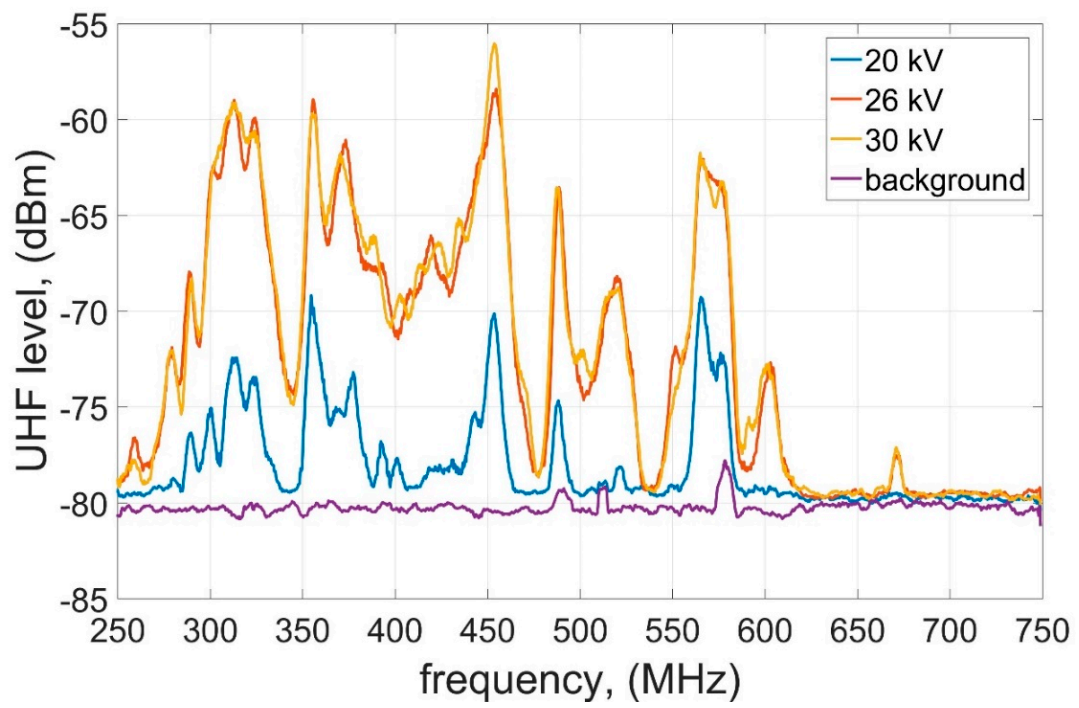

(a)

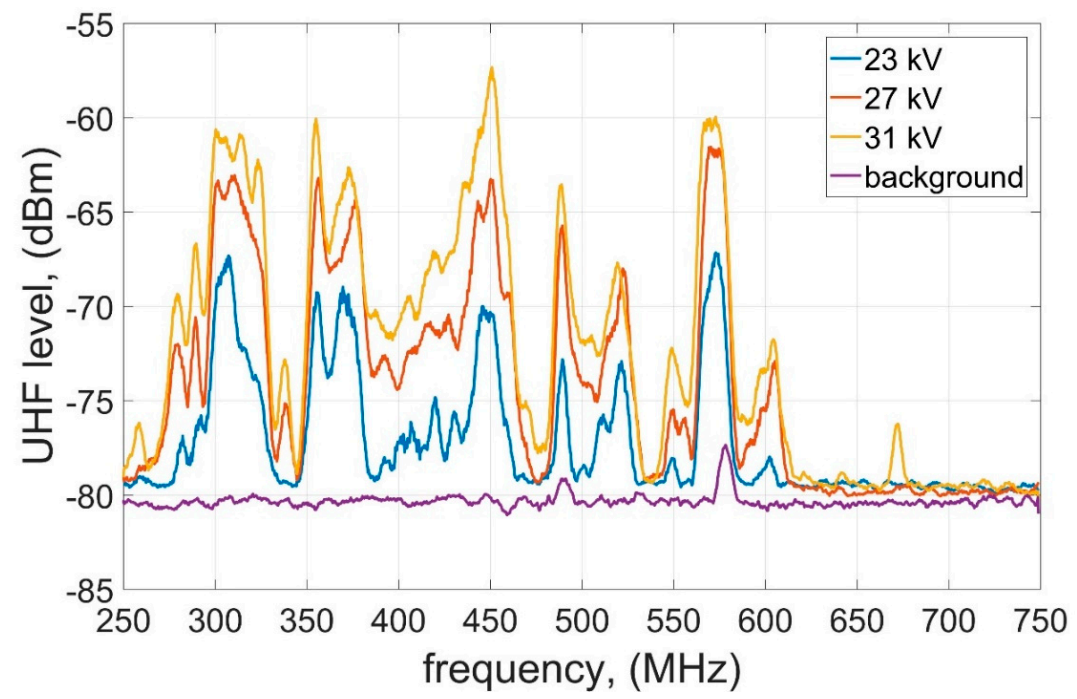

(b)

Figure 3. Levels of UHF signals emitted by surface partial discharges, generated in mineral oil on an electrode system with a solid dielectric made of: (a) Teflon, (b) glass. 


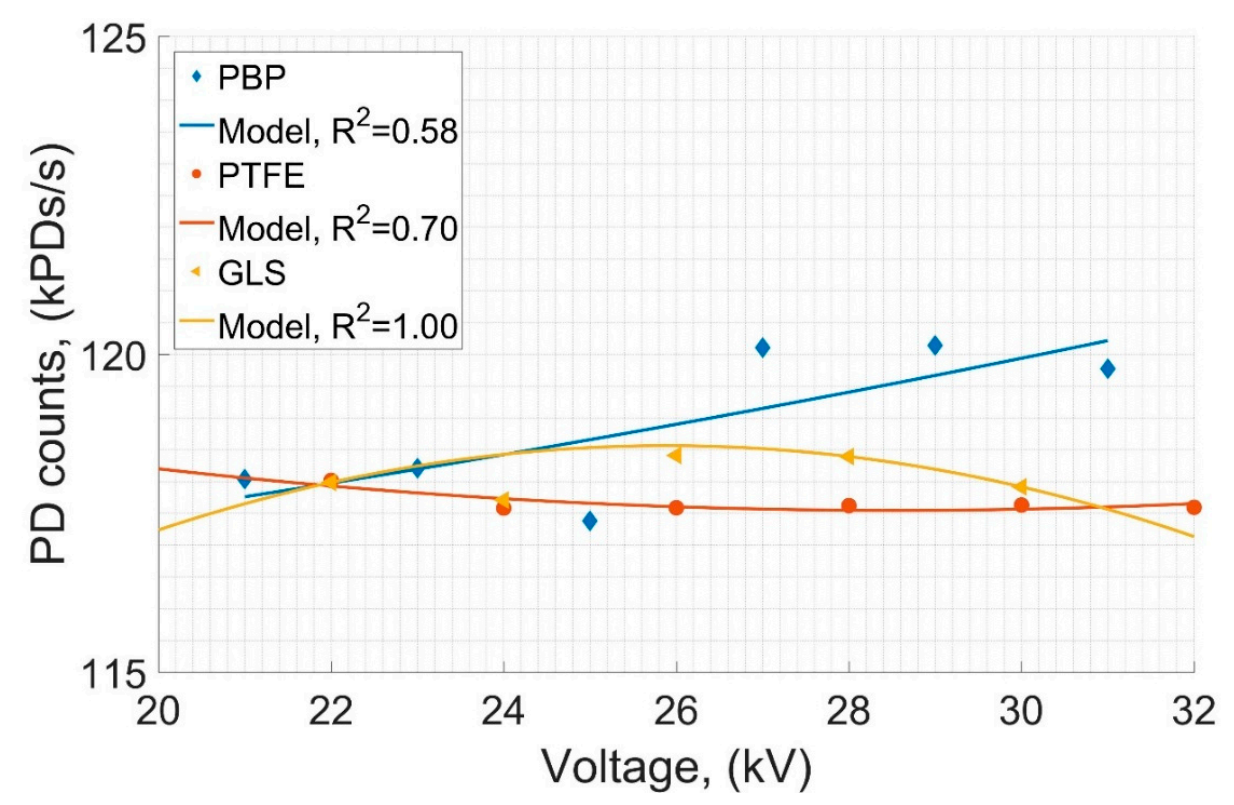

(a)

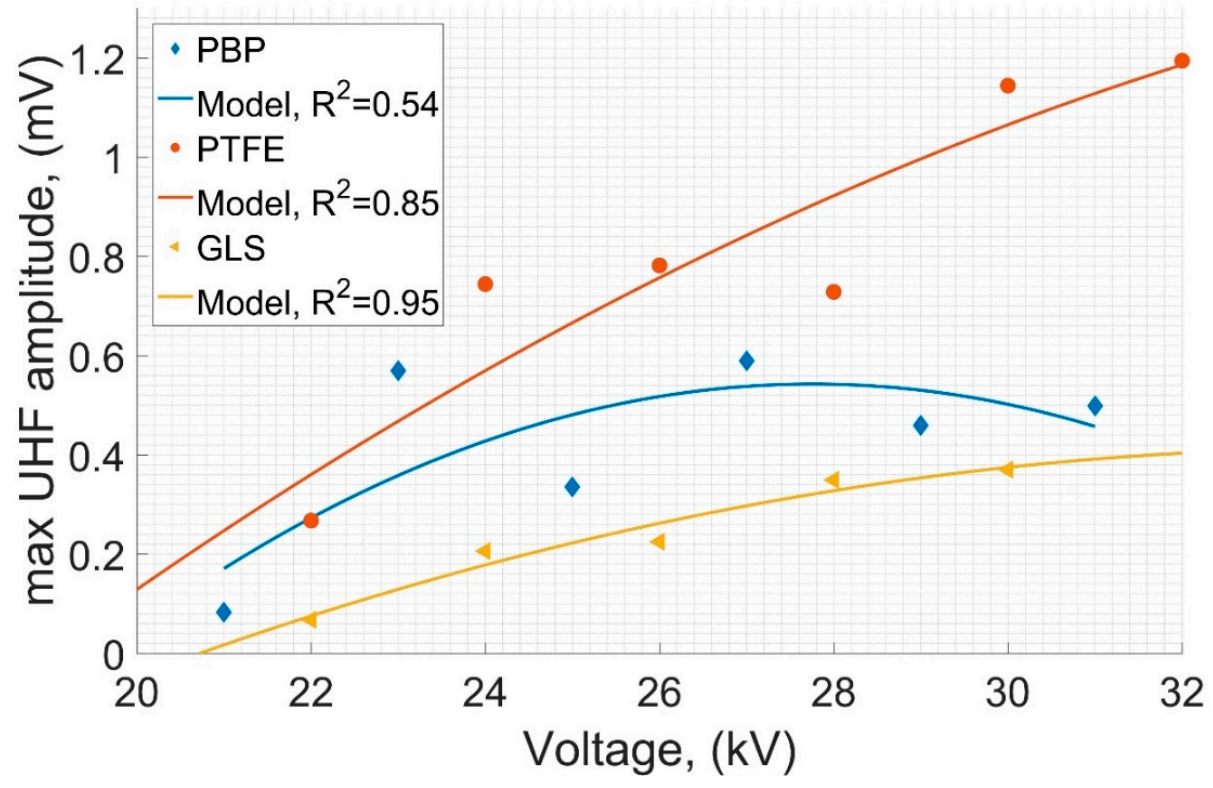

(b)

Figure 4. Characteristic parameters of the UHF signals in mineral oil: (a) partial discharge (PD) density for different dielectric materials; (b) Max UHF Voltage for different dielectric materials. 


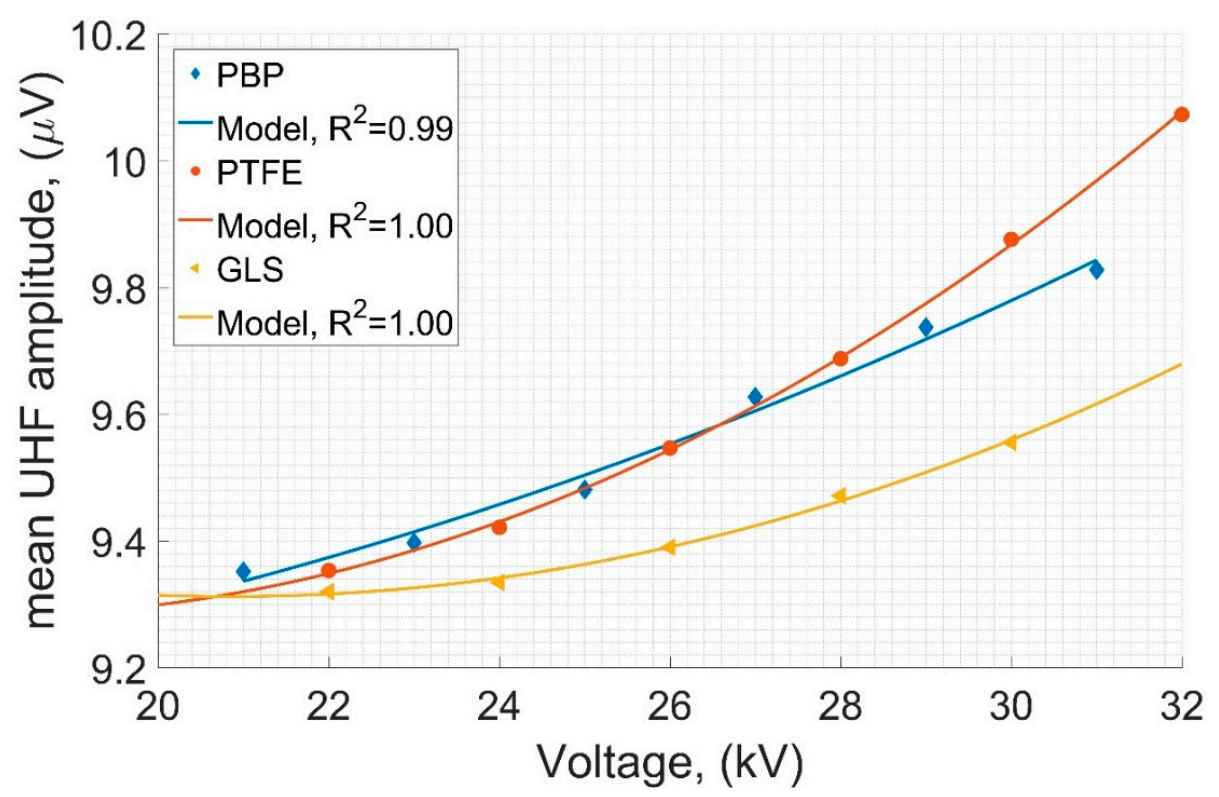

Figure 5. Characteristic parameters of the UHF signals in mineral oil: Mean UHF Voltage for different dielectric materials.

\subsubsection{Measurements in Air}

Measurements in the UHF range in air were carried out in identical metrological conditions for all tested systems, i.e., air temperature was $20^{\circ} \mathrm{C}$, humidity at the level of $51 \%$. External interference, which was recorded in all cases in the frequency range of $510 \mathrm{MHz}$ to about $600 \mathrm{MHz}$, was included as the background. As in the case of measurements in insulating oil, the first phase of UHF emission measurements included the analysis of individual frequency ranges of the measurement antenna in order to determine the bands for which the intensity of radio waves emissions was the highest. In this case, two center frequencies were selected: $380 \mathrm{MHz}$ and $500 \mathrm{MHz}$. These bands are repeatable in all tested systems and are characterized by the highest activity during the generation of surface partial discharges and negligibly small disturbances.

For each system, a series of measurements for three voltage values were made and background signals were recorded. As in the system where the environment of PD generation was oil, three types of dielectric solid materials were used in the air. For the pressboard, the voltages generating PD were equal: $4 \mathrm{kV}, 10 \mathrm{kV}$, and $16 \mathrm{kV}$. The UHF level is shown in Figure 6a. Figures $6 \mathrm{~b}$ and 7 show the measurements for Teflon and glass, respectively. In air research, it is worth noting that the stability of UHF level signals is highest for PBP, depending on the voltage generating PD. This is in contrast to the tests in oil where Teflon was the most stable, but only at higher voltages. Also for glass, a certain UHF level convergence can be observed for voltages up to $8 \mathrm{kV}$. Research on electromagnetic signals from partial discharges focuses on recording the EM wave in the range not only of UHF, but also of visible light. In the air, surface discharges generate large quantities of physical phenomena associated with the optical range. Glass as a transparent material at higher voltages generating partial discharges might mean that not every discharge act will be recorded. The dispersion of this unrecorded signal can cause interference in the recording of signals from other ranges. At higher PD generation voltages, more energy is generated in the visible light range, and at the same time, Figure 7 shows how the level of UHF signals becomes more intense. 


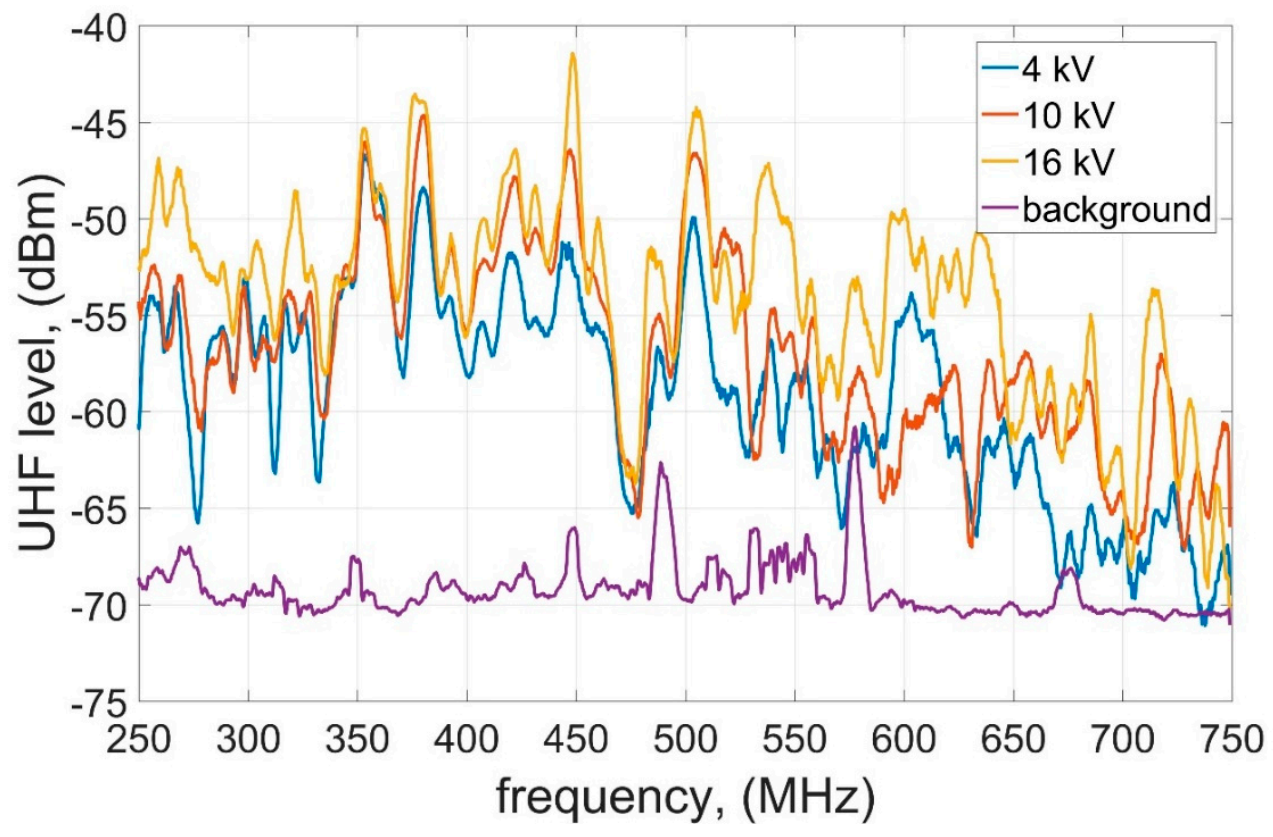

(a)

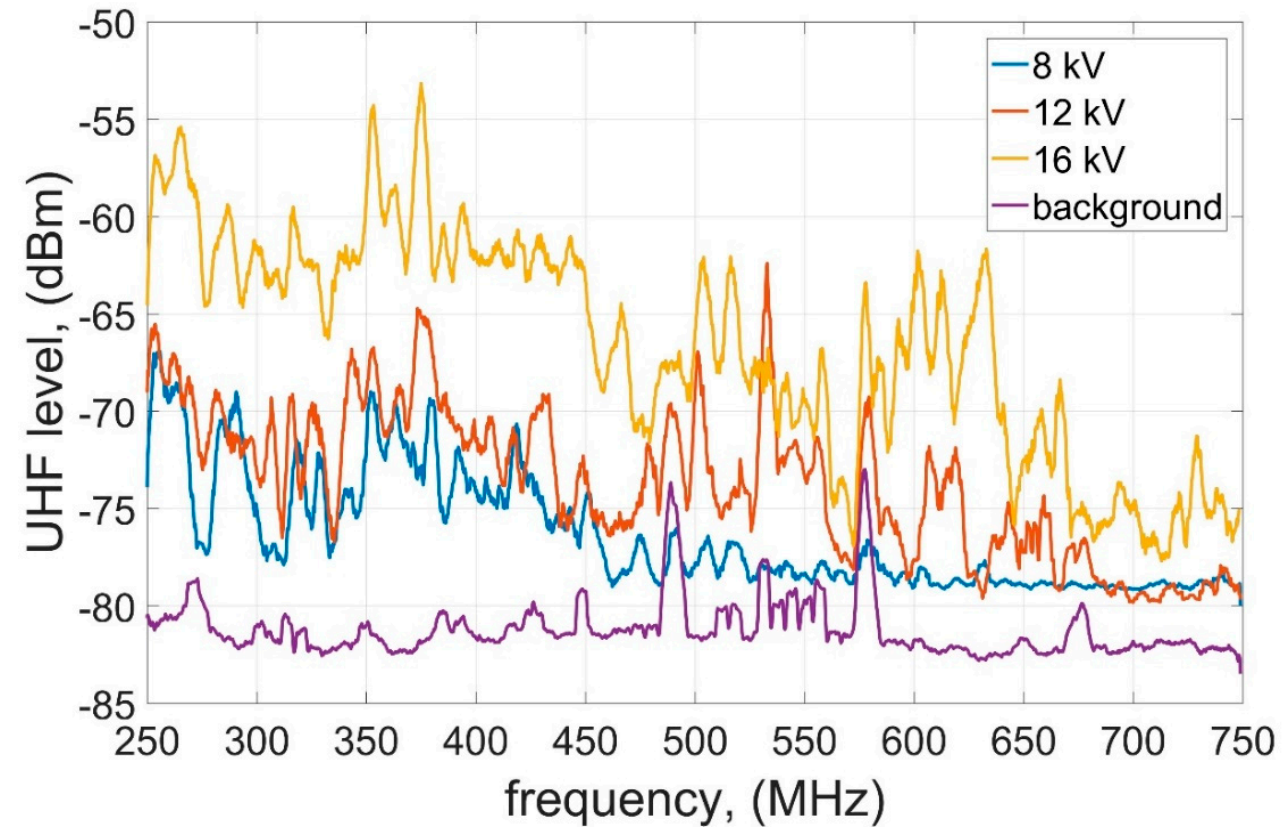

(b)

Figure 6. Levels of UHF signals emitted by surface partial discharges, generated in air on an electrode system with a solid dielectric made of: (a) Pressboard, (b) Teflon. 


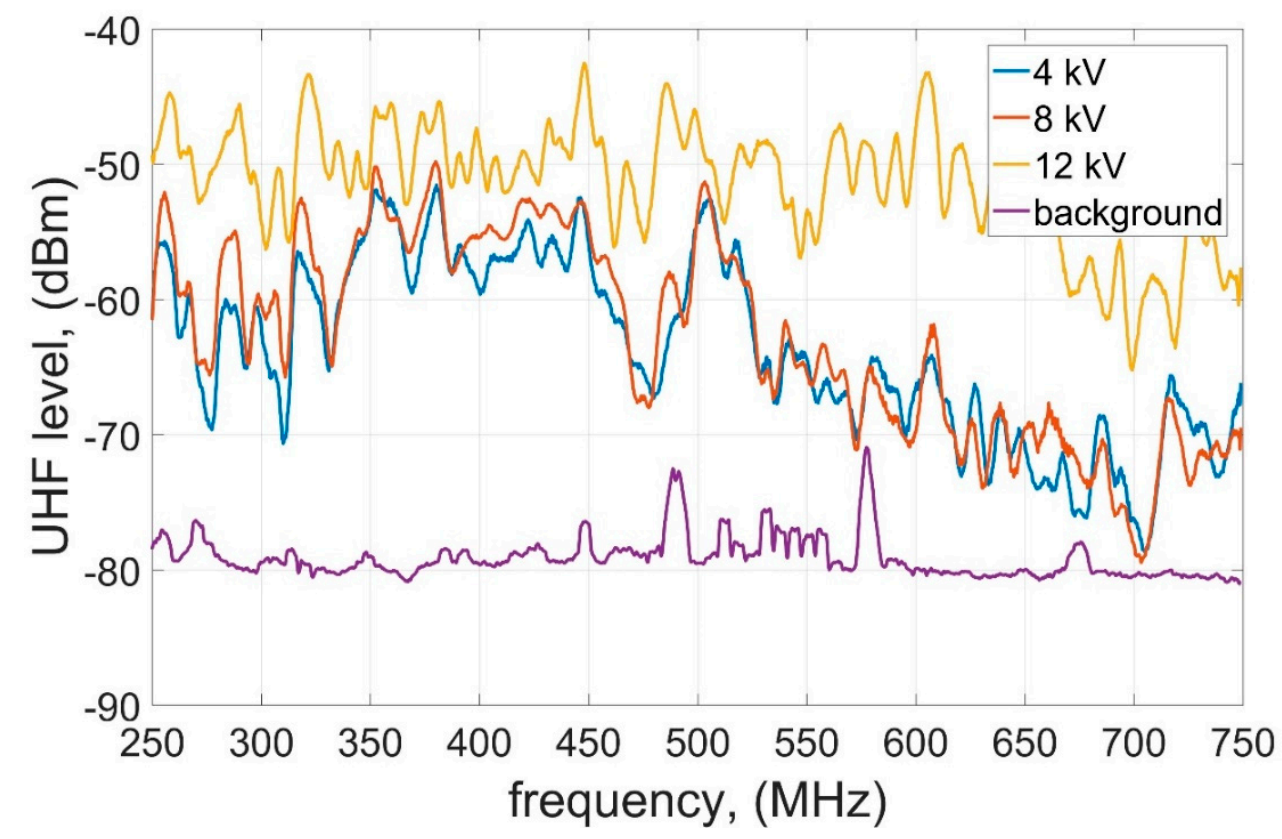

Figure 7. Levels of UHF signals emitted by surface partial discharges, generated in air on an electrode system with a solid dielectric made of glass.

Furthermore, during the generation of partial discharges in the air, apart from recording UHF, electrical, and optical signals, the number of PD acts for each dielectric material used was also recorded. The number of counts is shown in Figure 8a. Figures $8 \mathbf{b}$ and 9 show the average and maximum amplitude of UHF signals. The number of counts for Teflon and pressboard is more or less constant. For glass, the number of counts above certain voltage values increases rapidly as the PD generation voltage increases. Glass is transparent, so more signals from the borderline between UHF and other EM waves generated reach the analyzer. The average amplitude of the UHF signal is constant for each material for the entire measurement period. The highest values are recorded for glass and the lowest for Teflon. Very interesting results were obtained for measurements of maximum amplitude of UHF signals in the air. Figure $8 \mathrm{~b}$ clearly shows that, with the increase of voltage generating PD, the highest increase of amplitude is obtained for the pressboard. Similar values were also obtained for glass in the final phase of the experiment, although the initial amplitude is much higher. For PBP, the initial values are close to $\mu \mathrm{V}$. The maximum recorded UHF signal amplitude value for Teflon tests increases slightly and can be considered to be constant. 


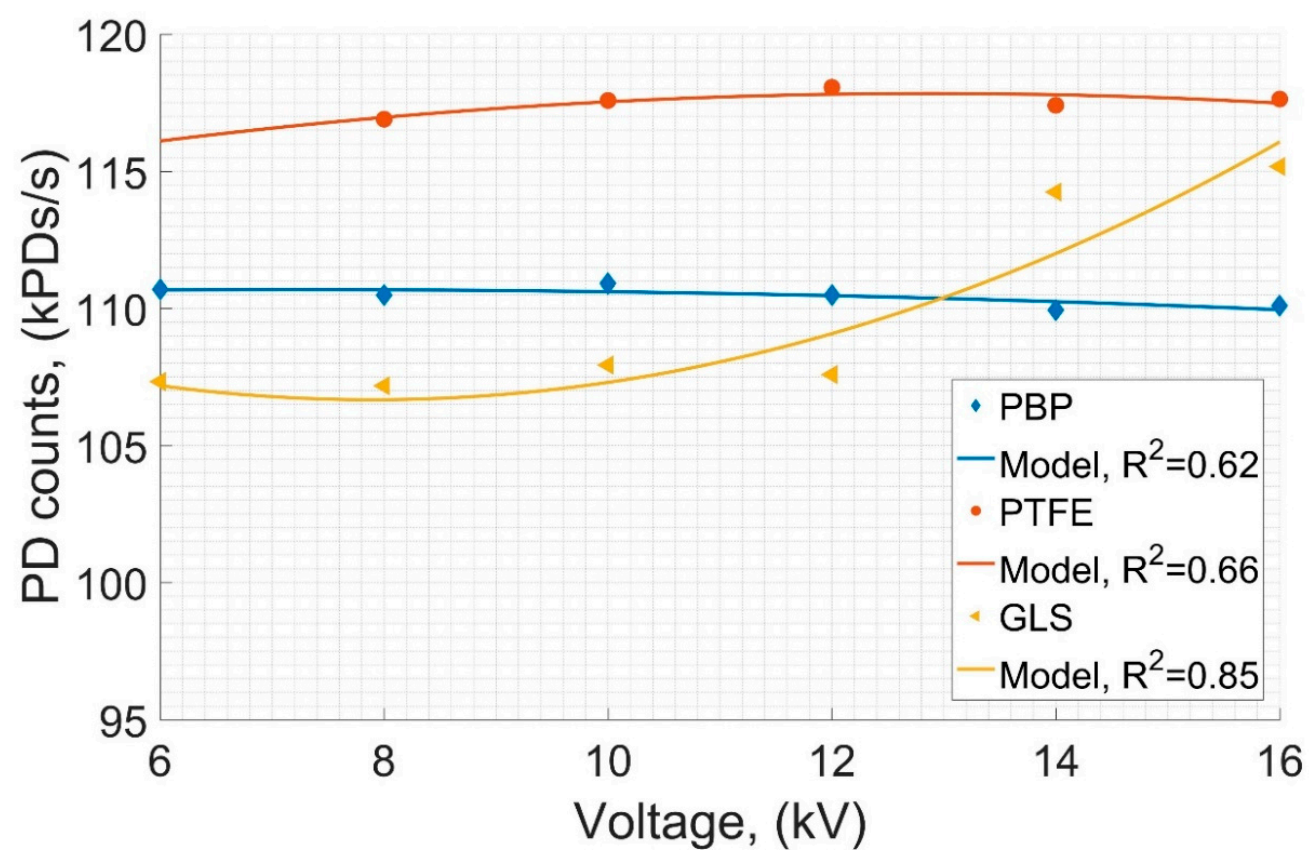

(a)

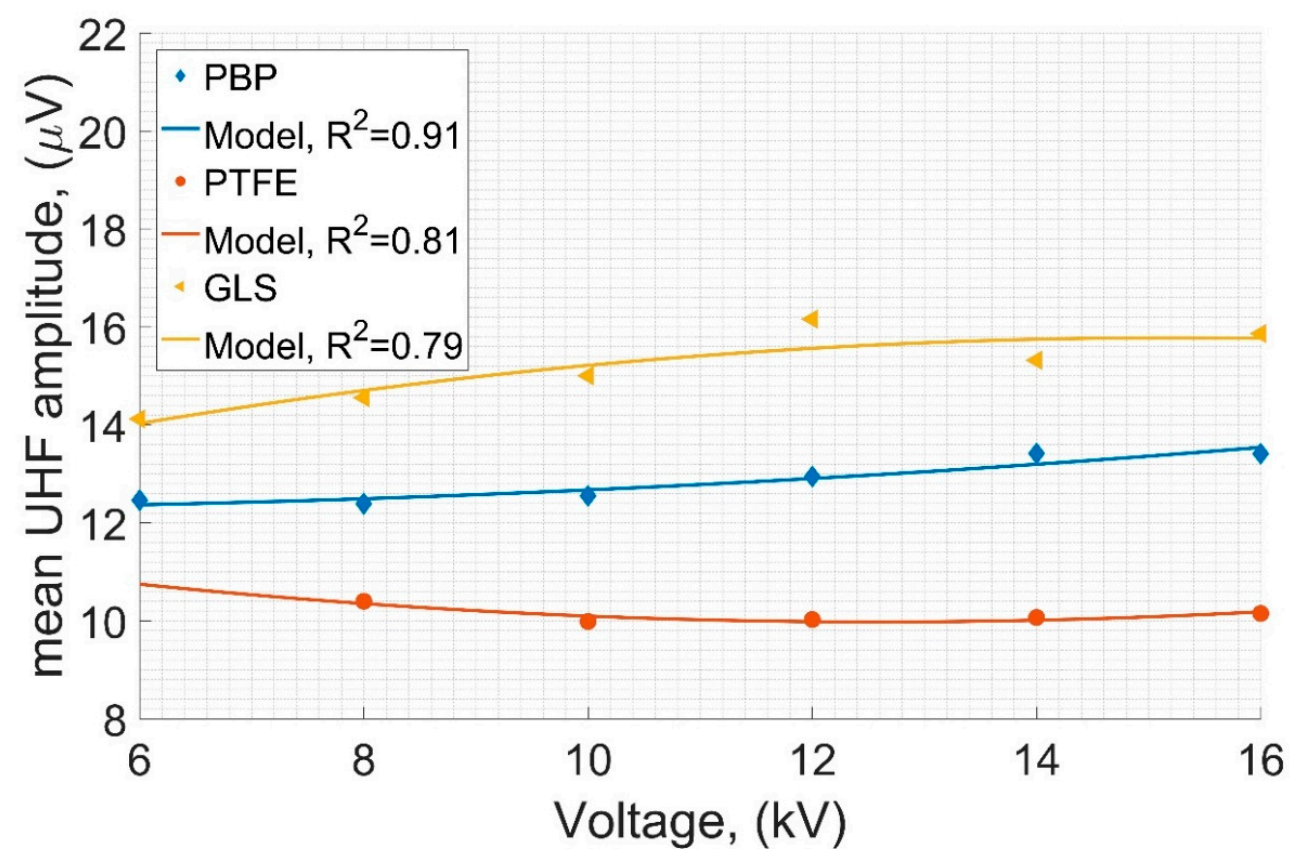

(b)

Figure 8. Characteristic parameters of the UHF signals in air: (a) PD density for different dielectric materials; (b) Max UHF Voltage for different dielectric materials. 


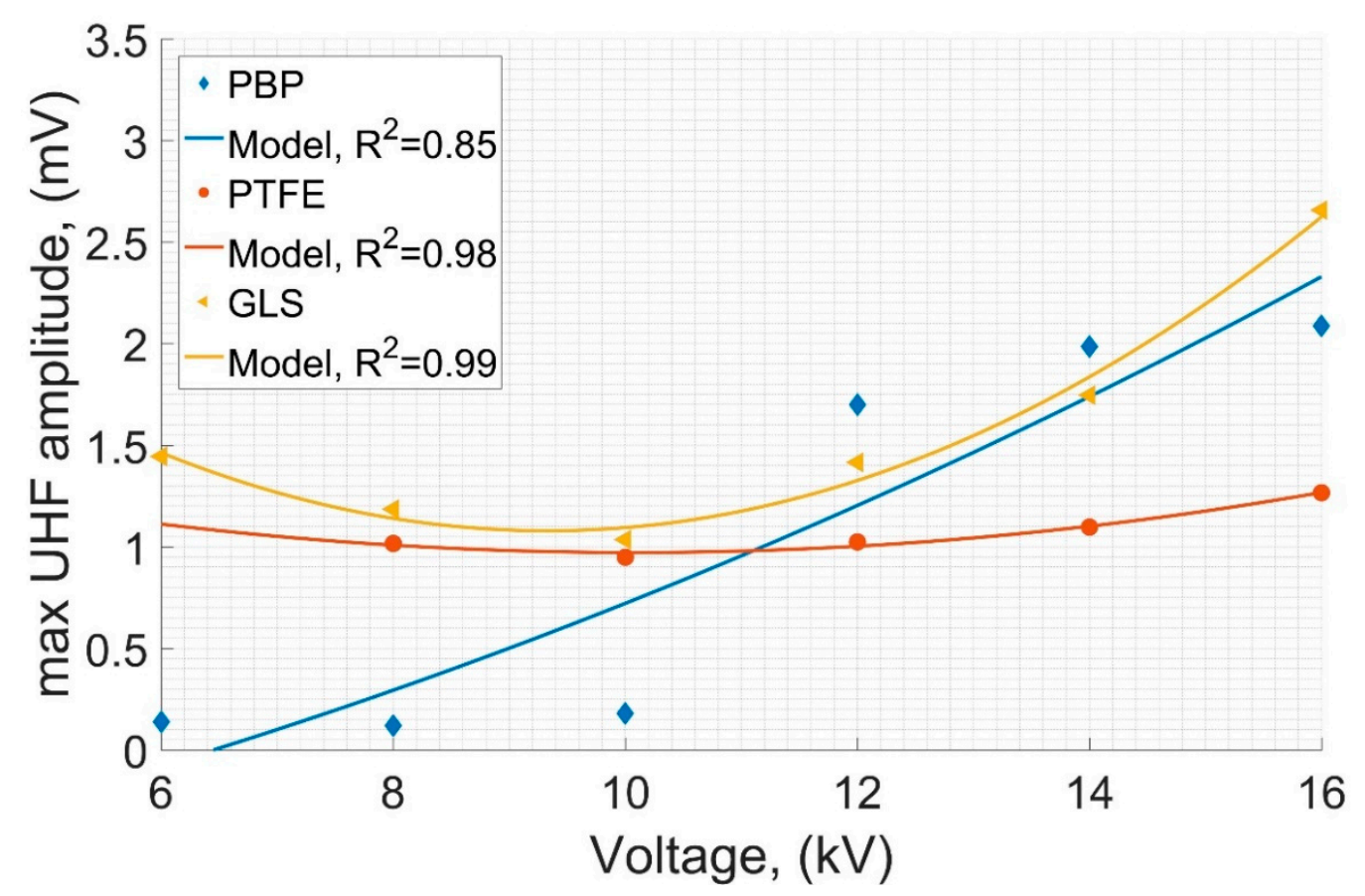

Figure 9. Characteristic parameters of the UHF signals in air: Mean UHF Voltage for different dielectric materials.

\subsection{Optical Spectrophotometry Measurements}

\subsubsection{Measurements in the Insulating Oil}

Measurement of optical radiation was carried out in parallel with the recording of radio waves in the UHF range for all three electrode systems. Emitted optical radiation was recorded in the UV-VIS-NIR range (wavelength range: $200-1100 \mathrm{~nm}$ ). The distance between the measuring head and the location of the discharge generation area was constant for all cases and amounted to $2.5 \mathrm{~cm}$. This distance was determined by the acceptance cone of the optical fiber. The adopted distance was also influenced by the metal casing of the optical fiber head. The recorded optical spectra are shown in Figures 10 and 11.

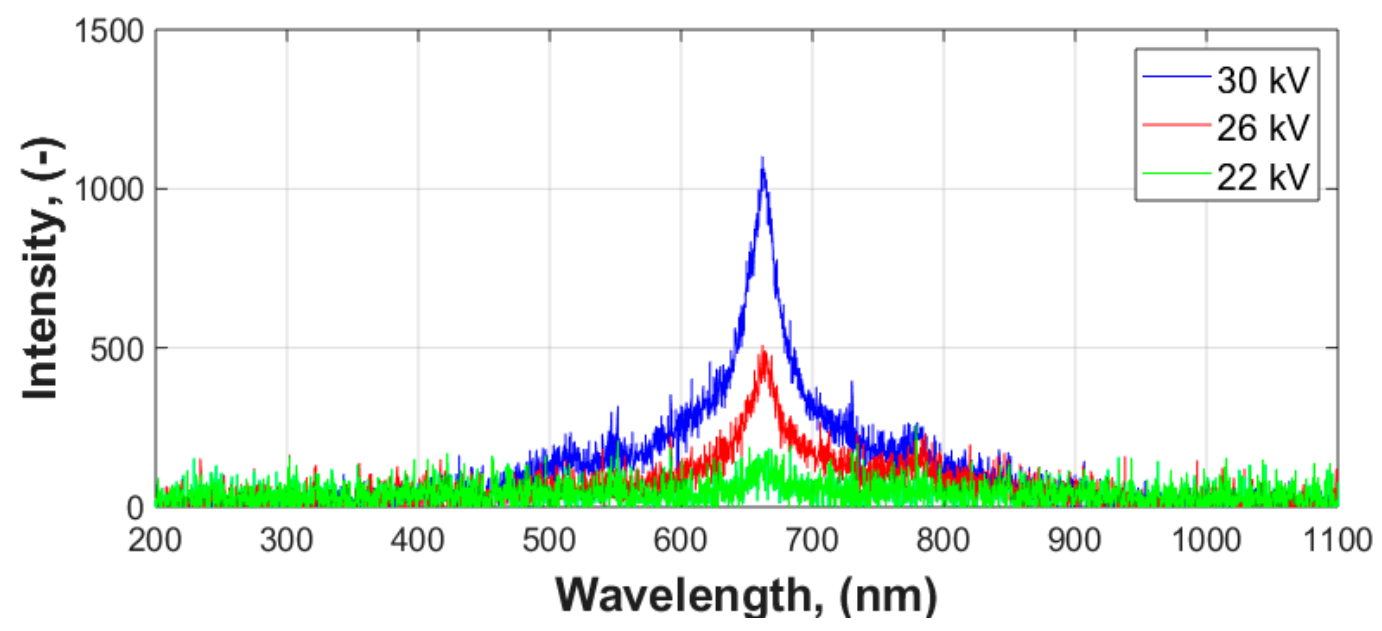

Figure 10. Optical spectra emitted by surface partial discharges in mineral oil on an electrode system with a solid dielectric made of pressboard. 


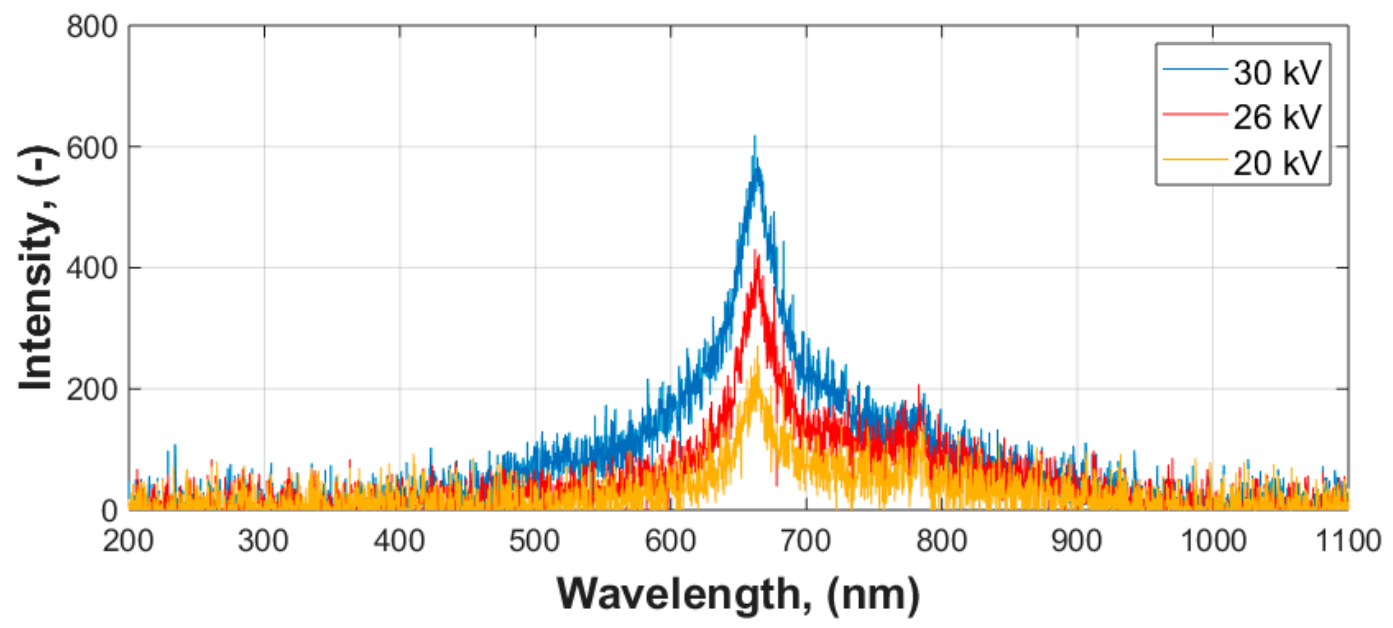

(a)

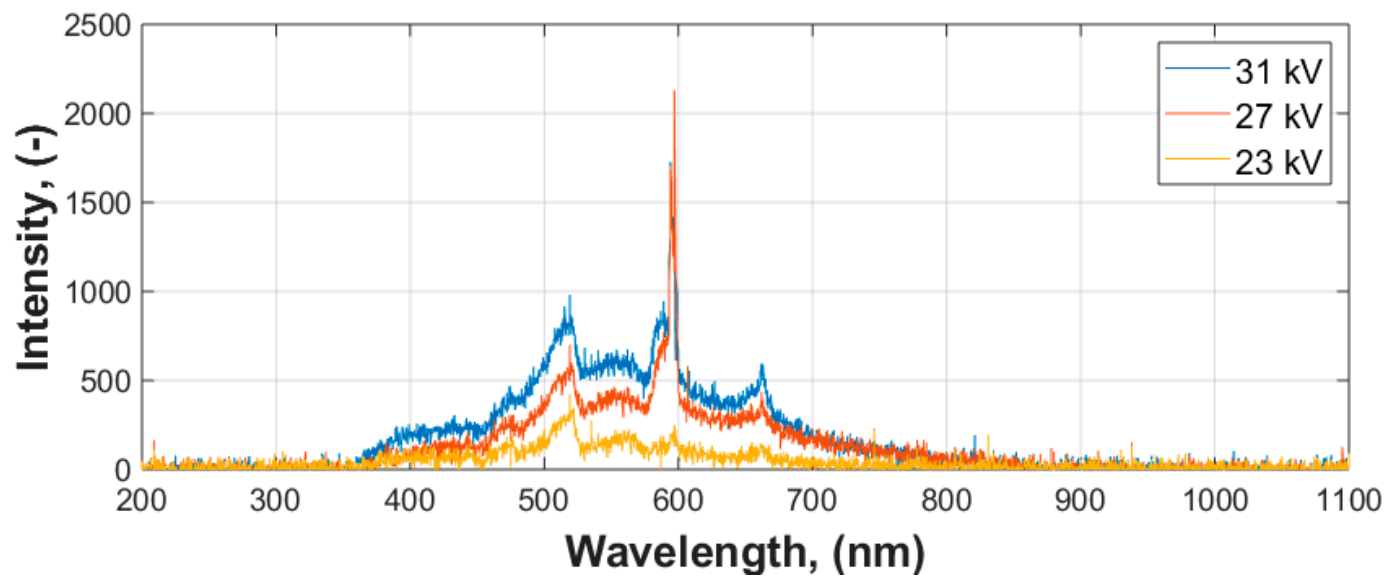

(b)

Figure 11. Optical spectra emitted by surface partial discharges in mineral oil on an electrode system with a solid dielectric made of: (a) Teflon, (b) glass.

The recorded optical spectra are continuous in the visible light range and band spectra, indicating the dominant intensity of wavelength components. The emission of optical radiation occurs mainly in the visible light range and low in the near infrared range. The lack of radiation in the ultraviolet range is caused by strong attenuation of this radiation range in the mineral oil. Identical spectra were obtained for the system with a dielectric from pressboard and Teflon, whereas significant differences occurred in the system with a glass dielectric. From the obtained optical spectra, the characteristic wavelengths with the highest intensity were found (Table 2).

Table 2. Dominant wavelength component for recorded optical spectra.

\begin{tabular}{ccc}
\hline $\begin{array}{c}\text { Electrode System with } \\
\text { Dielectric Made of: }\end{array}$ & $\begin{array}{c}\text { Dominant Wavelength } \\
\text { Component }(\mathbf{n m})\end{array}$ & $\begin{array}{c}\text { Recorded Spectral } \\
\text { Range (nm) }\end{array}$ \\
\hline Pressboard & $662 ; 787$ & $455-864$ \\
Teflon & $662 ; 787$ & $455-864$ \\
Glass & $522 ; 594 ; 662$ & $385-833$ \\
\hline
\end{tabular}

The dominant wavelength components were derived from the activation of chemical compounds. The measuring equipment used in this study did not allow for precise identification of particular chemical elements or compounds. However, the observed differences in dominant wavelengths and 
optical spectrum shapes indicated some influence of the dielectric type on the emitted optical radiation during surface electrical discharges in mineral oil.

\subsubsection{Measurements in the Air}

Optical radiation emitted by electrical discharges in the air was recorded mainly in the ultraviolet range. In contrast to the results recognised for measurements in oil, the optical spectra recorded in the air were band spectra. The obtained spectra were identical for all three tested systems and did not show any individual features that would allow them to be assigned to the individual dielectric types. Figure 12 presents the obtained optical spectra for each type of dielectric constant.

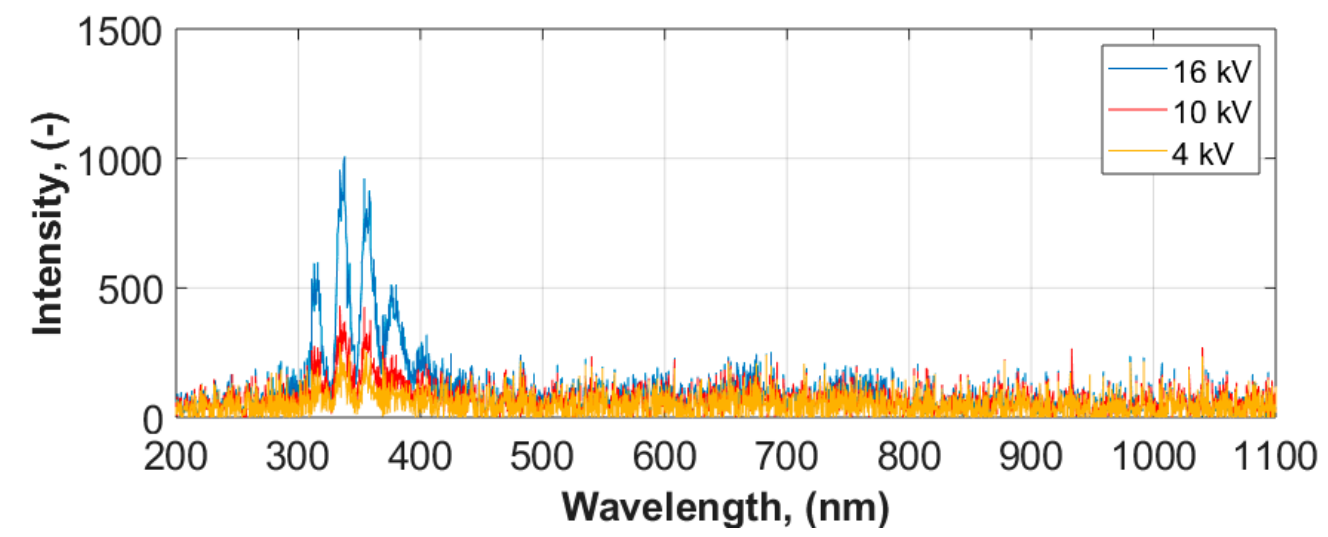

(a)

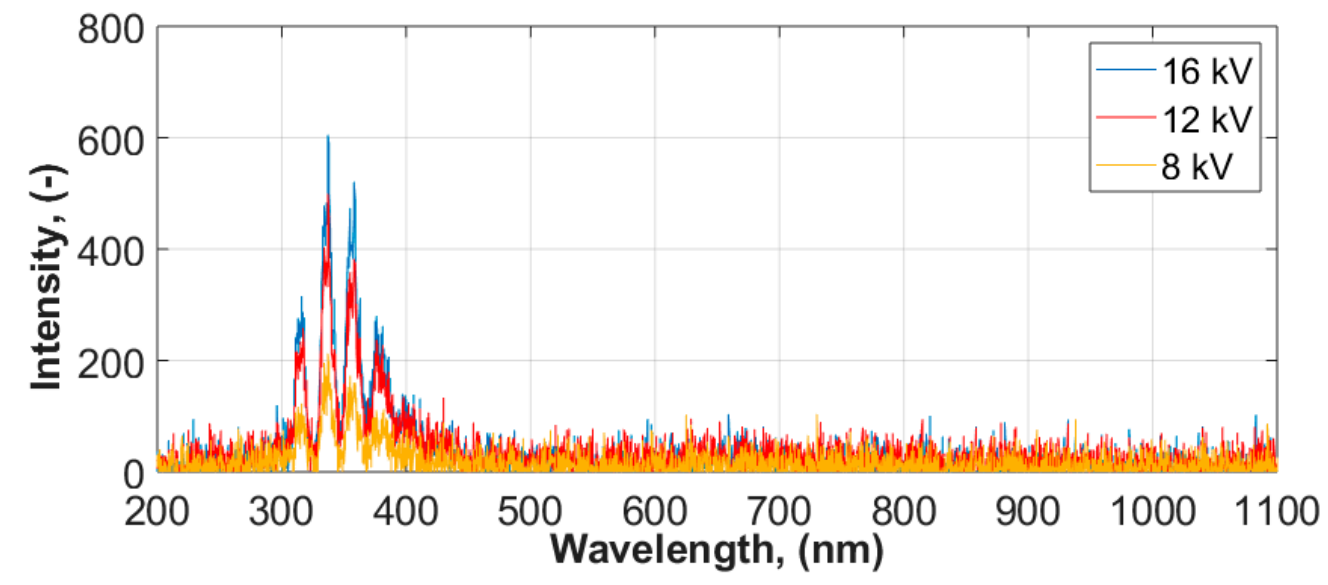

(b)

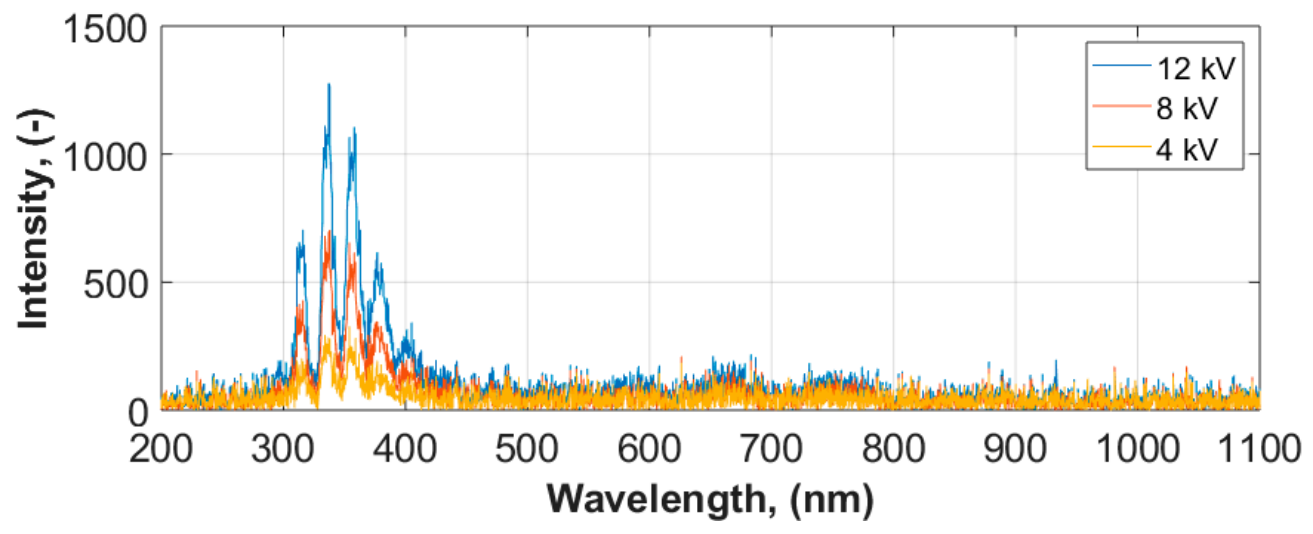

(c)

Figure 12. Optical spectra emitted by electric discharges in air on an electrode system with a solid dielectric made of: (a) Pressboard, (b) Teflon, (c) glass. 
Recorded optical spectra have a bandwidth character. The emission of optical radiation occurs mainly in the ultraviolet range (UV: $200-380 \mathrm{~nm}$ ) and partly in the visible light range (VIS: $380-780 \mathrm{~nm}$ ). This phenomenon is caused by the generation of surface electrical discharges in the air where there is a strong ionization of space around the high-voltage electrode. From the obtained optical spectra, the characteristic wavelengths with the highest intensity were found (Table 3), which are identical for all tested systems.

Table 3. Dominant wavelength component for recorded optical spectra in the air.

\begin{tabular}{ccc}
\hline $\begin{array}{c}\text { Electrode System with } \\
\text { Dielectric Made of: }\end{array}$ & $\begin{array}{c}\text { Dominant Wavelength } \\
\text { Component (nm) }\end{array}$ & $\begin{array}{c}\text { Recorded Spectral } \\
\text { Range (nm) }\end{array}$ \\
\hline Pressboard, Teflon, Glass & $316 ; 334 ; 354 ; 377 ; 401$ & $289-450$ \\
\hline
\end{tabular}

\section{Conclusions}

Obtained results of measurements carried out under the same metrological conditions indicate that the kind of material that the permanent dielectric was made of may have a potential impact for some ranges of emitted electromagnetic waves during the generation of surface electric discharges.

For tests carried out in mineral oil, the number of PD counts registered in the UHF range was the highest for a system with a solid dielectric made of pressboard. However, for the other two systems, the number of PD counts was similar. The amplitude analysis of the UHF signal showed that, under the same metrological conditions, the strongest emitted signal occurred during the generation of surface electrical discharges on the systems with a dielectric made of Teflon and pressboard.

For tests carried out in the air, the number of PD counts recorded in the UHF range was the highest for the system with a solid dielectric made of Teflon. In turn, the analysis of the UHF signal amplitude in the air showed that the strongest emitted signal occurred during the generation of surface electric discharges on systems with a solid dielectric made of glass and the weakest on a system with Teflon.

Registered optical spectra showed individual spectral characteristics only in the case of optical radiation emitted by surface electric discharges in mineral oil. The system with a solid dielectric made of glass showed significant differences in the optical spectrum. These differences may result from the density of glass, which was the highest of all three materials used (glass $2.5 \mathrm{~g} / \mathrm{cm}^{3}$, Teflon $2.2 \mathrm{~g} / \mathrm{cm}^{3}$, pressboard 1.0-1.3 g/ $\mathrm{cm}^{3}$ ), and the surface structure on which the electrical discharge was generated. However, the optical spectra obtained for surface discharges in air were identical for all three systems. This is due to the mechanism of formation and generation of surface electrical discharges in the air.

The obtained results can be used to select materials for the construction of high-voltage insulation systems. They will also be helpful in designing high-voltage diagnostic systems and creating specialized knowledge bases.

Author Contributions: Conceptualization, M.K. (Michał Kozioł), Ł.N.; methodology, M.K. (Michał Kozioł), M.K. (Michał Kunicki); formal analysis, M.K. (Michał Kozioł), Ł.N., and M.K. (Michał Kunicki); validation, Ł.N., M.K. (Michał Kunicki); resources, I.U.; data curation, Ł.N., I.U.; writing-original draft preparation, M.K. (Michał Kozioł); writing-review and editing, Ł.N., M.K.(Michał Kunicki), and I.U.; project administration, M.K.(Michał Kozioł).

Funding: This research was cofunded by National Science Centre, Poland (NCN) as a part of the Preludium Research Project No. 2017/25/N/ST8/00590.

Conflicts of Interest: The authors declare no conflict of interest. The founding sponsors had no role in the design of the study; in the collection, analyses, or interpretation of data; in the writing of the manuscript, and in the decision to publish the results. 


\section{References}

1. Kozioł, M.; Nagi, Ł.; Kunicki, M.; Urbaniec, I. Analysis of Radiation in the UHF and Optical Range Emitted by Surface Partial Discharges. In Proceedings of the 2019 IEEE 19th International Conference on Environment and Electrical Engineering and 2019 IEEE 3rd Industrial and Commercial Power Systems Europe, EEEIC/I and CPS Europe 2019, Genoa, Italy, 11-14 June 2019.

2. IEEE Recommended Practice for Partial Discharge Measurement in Liquid-Filled Power Transformers and Shunt Reactors; IEEE Std. C57.113; IEEE: Piscataway, NJ, USA, 2010.

3. Kunicki, M. Variability of the UHF Signals Generated by Partial Discharges in Mineral Oil. Sensors 2019, 19, 1392. [CrossRef] [PubMed]

4. Beura, C.P.; Beltle, M.; Tenbohlen, S. Positioning of UHF PD Sensors on Power Transformers Based on the Attenuation of UHF Signals. IEEE Trans. Power Deliv. 2019, 34, 1520-1529. [CrossRef]

5. Kunicki, M.; Cichon, A. Application of a phase resolved partial discharge pattern analysis for acoustic emission method in high voltage insulation systems diagnostics. Arch. Acoust. 2018, 43, 235-243.

6. Wotzka, D.; Koziol, M.; Nagi, L.; Urbaniec, I. Experimental analysis of acoustic emission signals emitted by surface partial discharges in various dielectric liquids. In Proceedings of the 2018 IEEE 2nd International Conference on Dielectrics, ICD 2018, Budapest, Hungary, 1-5 July 2018; pp. 1-5.

7. Jongvilaikasem, K.; Maneerot, S.; Jariyanurat, K.; Pattanadech, N. Comparison of Dissolved Gases in Natural Ester under Partial Discharges. In Proceedings of the 2019 IEEE 20th International Conference on Dielectric Liquids (ICDL), Roma, Italy, 23-27 June 2019; pp. 1-4.

8. Dincer, S.; Duzkaya, H.; Tezcan, S.S.; Dincer, M.S. Analysis of Insulation and Environmental Properties of Decomposition Products in SF6-N2 Mixtures in the Presence of $\mathrm{H}_{2} \mathrm{O}$. In Proceedings of the 2019 IEEE International Conference on Environment and Electrical Engineering and 2019 IEEE Industrial and Commercial Power Systems Europe (EEEIC/I CPS Europe), Genova, Italy, 11-14 June 2019; pp. 1-6.

9. Koziol, M.; Nagi, L. Analysis of Optical Radiation Spectra Emitted by Electrical Discharges, Generated by Different Configuration Types of High Voltage Electrodes. In Proceedings of the 2018 IEEE 2nd International Conference on Dielectrics, ICD 2018, Budapest, Hungary, 1-5 July 2018; pp. 1-4.

10. Baug, A.; Choudhury, N.R.; Ghosh, R.; Dalai, S.; Chatterjee, B. Identification of single and multiple partial discharge sources by optical method using mathematical morphology aided sparse representation classifier. IEEE Trans. Dielectr. Electr. Insul. 2017, 24, 3703-3712. [CrossRef]

11. Karmakar, S.; Meshram, S.; Kalathiripi, H. Evaluation of Partial Discharge Aged Transformer Oil Using Optical Spectroscopy Techniques. In Proceedings of the 2019 International Conference on High Voltage Engineering and Technology (ICHVET), Hyderabad, India, 7-8 February 2019; pp. 1-5.

12. Kozioł, M.; Boczar, T.; Nagi, L. Identification of electrical discharges forms, generated in insulating oil, using the optical spectrophotometry method. IET Sci. Meas. Technol. 2019, 13, 416-425. [CrossRef]

13. Ma, G.; Zhou, H.; Zhang, M.; Li, C.; Yin, Y.; Wu, Y. A High Sensitivity Optical Fiber Sensor for GIS Partial Discharge Detection. IEEE Sens. J. 2019, 19, 9235-9243. [CrossRef]

14. Siegel, M.; Coenen, S.; Beltle, M.; Tenbohlen, S.; Weber, M.; Fehlmann, P.; Hoek, S.M.; Kempf, U.; Schwarz, R.; Linn, T. Calibration Proposal for UHF Partial Discharge Measurements at Power Transformers. Energies 2019, 12, 3058. [CrossRef]

15. Nagi, Ł.; Kozioł, M.; Wotzka, D. Analysis of the spectrum of electromagnetic radiation generated by electrical discharges. IET Sci. Meas. Technol. 2019, 13, 812-817. [CrossRef]

16. Shin, J.; Kim, S.; Kim, E.; Jo, H.; Sample, A.V. Partial Discharge Induction with X-rays to Detect Void Defects in Solid Insulating Materials. In Proceedings of the 2018 Condition Monitoring and Diagnosis (CMD), Perth, Australia, 23-26 September 2018; pp. 2-4.

17. Rozga, P.; Stanek, M.; Rapp, K. Lightning properties of selected insulating synthetic esters and mineral oil in point-to-sphere electrode system. IEEE Trans. Dielectr. Electr. Insul. 2018, 25, 1699-1705. [CrossRef]

18. Pasternak, B.; Rózga, P.; Rapp, K. Influence of Location of Pressboard Barrier on the Development of Electrical Discharges in Synthetic Esters and Mineral Oil at Negative LIV. In Proceedings of the 2019 IEEE 20th International Conference on Dielectric Liquids (ICDL), Roma, Italy, 23-27 June 2019; pp. 1-4.

19. Li, X.; Li, J.; Jiang, T.; Wang, Y.; Huang, Z. Analysis of creeping discharges on oil-impregnated pressboard under combined AC and DC voltages. IEEE Trans. Dielectr. Electr. Insul. 2018, 25, 2380-2388. [CrossRef] 
20. Li, S.; Li, Q.; He, D. PD Classification in Oil-pressboard Insulation by Simulating a Needle-Plane Model with + DC Voltage. IEEE Trans. Dielectr. Electr. Insul. 2019, 26, 261-269. [CrossRef]

21. Kunicki, M.; Cichoń, A.; Nagi, Ł. Statistics based method for partial discharge identification in oil paper insulation systems. Electr. Power Syst. Res. 2018, 163, 559-571. [CrossRef]

(C) 2019 by the authors. Licensee MDPI, Basel, Switzerland. This article is an open access article distributed under the terms and conditions of the Creative Commons Attribution (CC BY) license (http://creativecommons.org/licenses/by/4.0/). 